\title{
A CASE STUDY OF PROSODIC PHRASAL GROUPING AND INTONATIONAL PROMINENCE IN LANGUAGE ACQUISITION
}

\author{
Susanto \\ English Education Study Program, Bandar Lampung University, Indonesia \\ E-mail: susanto@ubl.ac.id
}

APA Citation: Susanto. (2016). A case study of prosodic phrasal grouping and intonational prominence in language acquisition. English Review, 4(2), 289-295

Received: 23-02-2016

Accepted: 28-03-2016

Published: 01-06-2016

Abstract: In language acquisition, children use prosody in their comprehension and production of utterances. In line with that, as a case study in this research, I analyze two particular aspects of prosody in a child's language acquisition, i.e. prosodic phrasal grouping and intonational prominence. In the first aspect, I investigate whether the child uses prosodic phrases to group words together into interpretable units. In the second aspect, I analyze whether the child uses intonational prominence to focus marking prosody. The result indicates that both aspects are used by the child.

Keywords: language acquisition, prosody, intonation, phonetic cues.

\section{INTRODUCTION}

In the acquisition of a language, children use prosody in their comprehension and production of utterances and they are sensitive to prosody's rhythmic and melodic patterns (Ito, 2002). They can discriminate between two spoken languages on the basis of their prosody (Mehler et al., 1988), and use various aspects of prosody to determine the location of words in the stream of running speech (Morgan \& Saffran, 1995; Morgan, 1996; Johnson \& Jusczyk, 2001).

Children are also sensitive to correspondences among the acoustic aspects of prosodic phrasing when they listen to sentences, and they tend to pronounce their own utterances with appropriate affective and phrasal prosody (Mandel, Jusczyk \& Pisoni, 1995; Katz et al., 1996). As the children's knowledge of their native language becomes more adult-like, they eventually develop the use of the full complement of prosodic functions such as focus prosody. Children are capable of processing prosodic prominence that express focus or contrast in a discourse (Ito \& Speer, 2006; Weber, Braun, \& Crocker, 2006).

In the research, I analyze two particular aspects of prosody in a child's language acquisition, i.e. prosodic phrasal grouping, and intonational prominence. In the first aspect, I investigate whether the child uses prosodic phrases to group words together into interpretable units. In the second aspect, I analyze whether the child uses intonational prominence to focus marking prosody.

\section{METHOD}

For the data, a monologue spoken a child $(\mathrm{R}, 6 ; 01)$ was recorded by using Sony IC RECORDER ICD-PX720 in SHQ (Super 
High Quality) recording mode. The child is bilingual (Indonesian and English). In the monologue, the child was explaining in English how his toy worked. The sound is in a WAVE file with 120,4 seconds in length. The sound is analyzed acoustically in Praat (Boersma \& Weenink, 2012). For analyzing the prosody, I use a systemic phonological approach for Tonality - chunking of speech into tone groups; and Tonicity - identifying tonic syllable in a given tone group (Halliday \& Greaves, 2008).

\section{RESULTS AND DISCUSSION}

From investigating the speech of the child, the analysis shows that the child used prosodic phrases to group together words that should be comprehended together as coherent units. The using of prosodic phrases is exemplified in Fig 1, 2, and 3. To some extent, utterances of the child are not grammatically wellformed.

Fig. 1 shows that the child chunks his utterances into three tone groups: // there's a people on it // and // this is for //. The clause with existential process 'there's a people on it' is uttered in unmarked tonality. The tone groups are separated by appreciable pauses. Mostly, clear pauses also separate the child's tone groups as observed in Fig. 2 and Fig. 3.

Fig. 1: The child's utterance 'There's a people on it here' // there's a people on it // and // this is for //

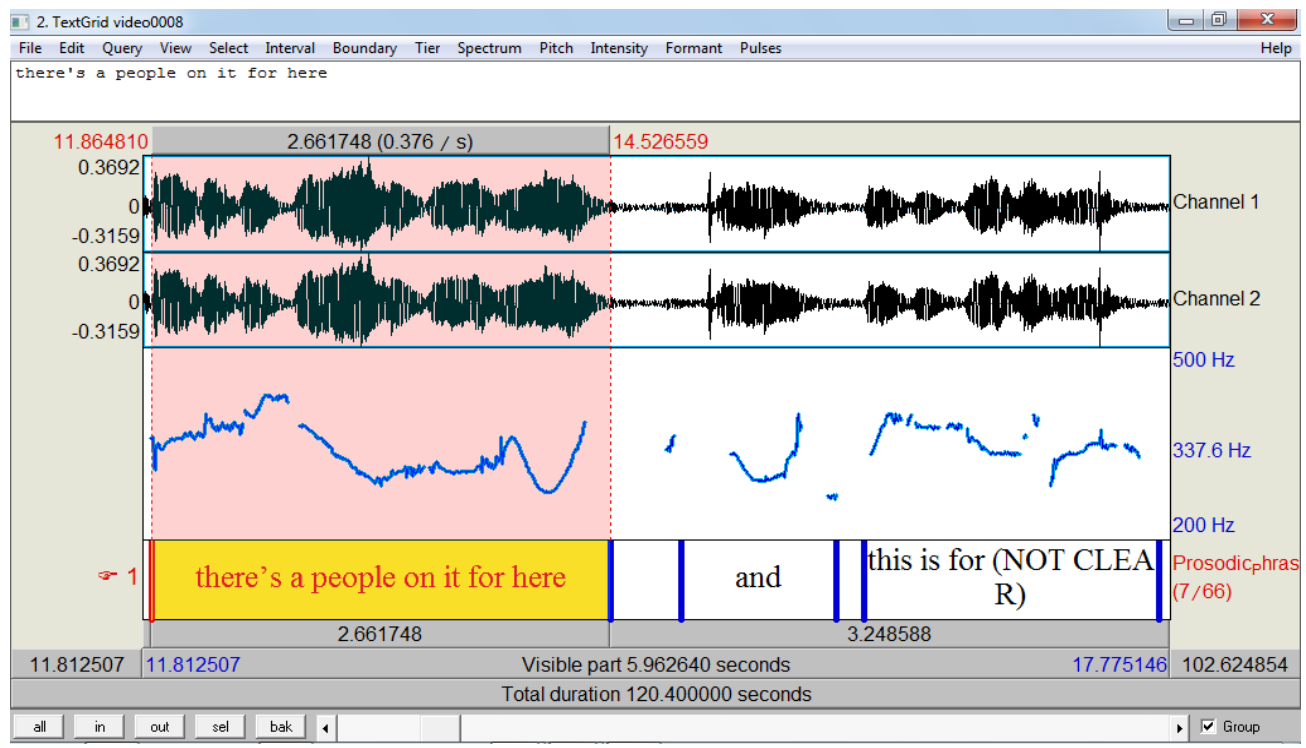

In Fig. 2, it is seen that the child chunks a clause into two tone groups: / / this is for // the sound wave //. It is interesting to note that the child does not make the prepositional phrase 'for the sound wave' club together. It can be interpreted that the child takes time to think the content for the circumstance. But, in fact, the child has anchored the information by attaching the preposition 'for' with participant + relational process 'this is for'. 
Fig. 2: The child's utterance 'This is for the sound wave' // this is for // the sound wave //

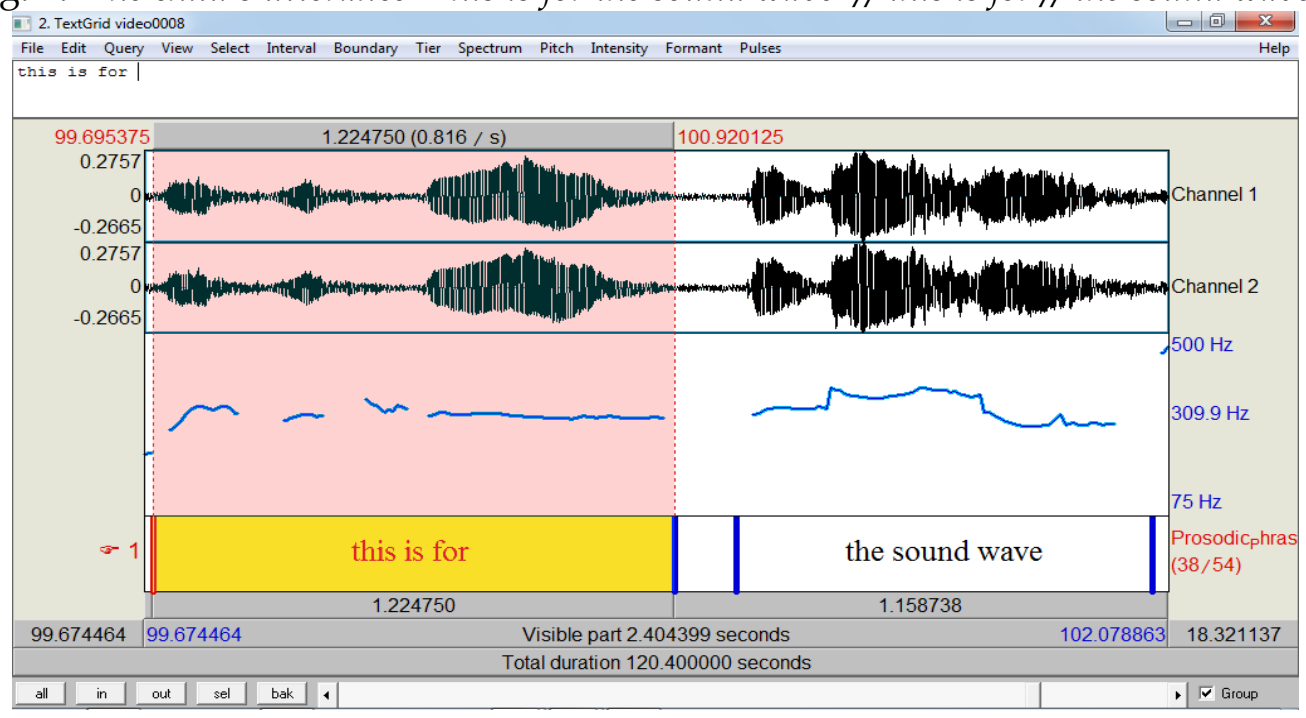

The child does the same for another clause 'Well, everyone, thanks watching my $t^{\prime}$, i.e. two tone groups for the clause: // well everyone // thanks watching my tv // as exemplified in Fig. 3. In the utterance, the child club 'everyone', functioning as vocative, neither together with mental process + participant 'thanks watching my $\mathrm{tv}^{\prime}$ nor in a separate tone group. The child clubs it together with 'well', functioning as continuative, instead.

Fig. 3: The child's utterance 'Well, everyone, thanks watching my tv' // well everyone // thanks watching

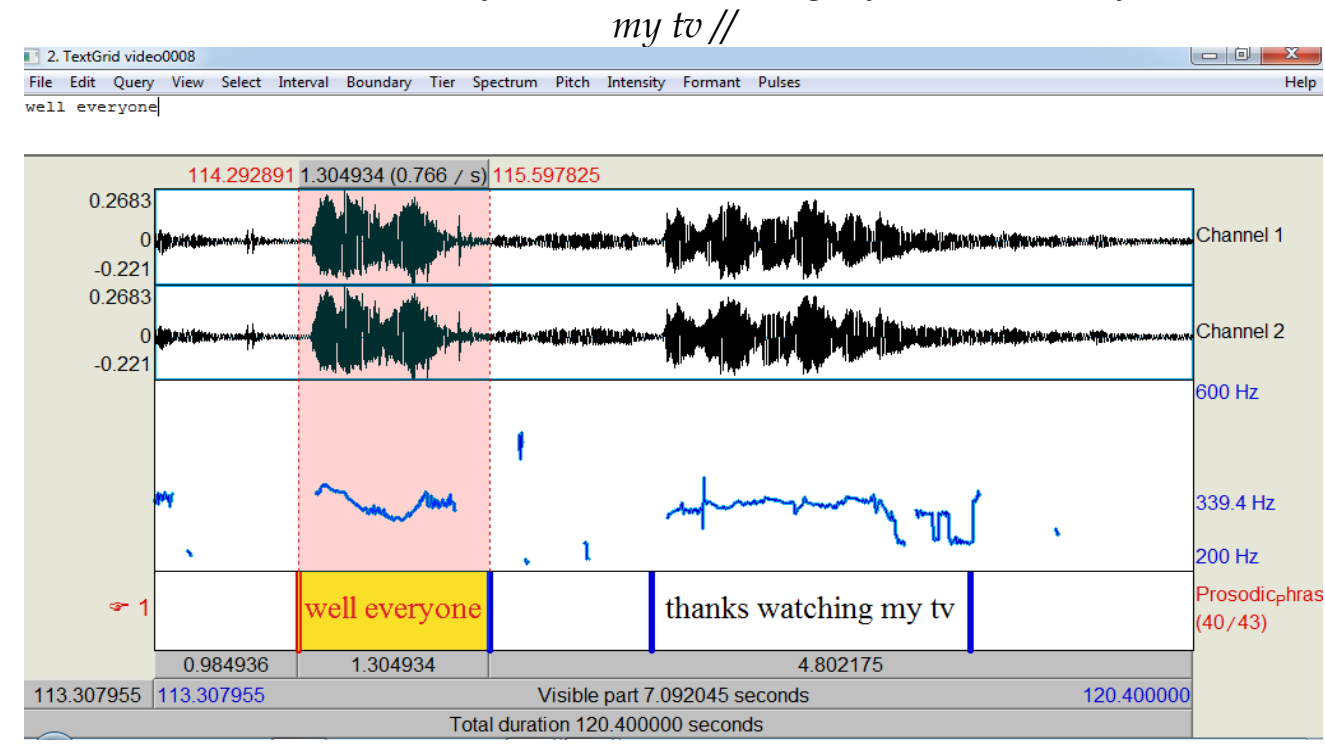

From the analysis, it is also examined if the child uses prosodic prominence for expressing information focus. The finding shows that it is noticeable and the child does as exemplified in Fig. 4, 5, and 6. As seen in Fig. 4, the focus is antenna in the utterance "it has antenna' since the tonic syllable is on *TEN. The tonic syllable is more salient than the other syllables referring to amplitude, duration and change of pitch. 
Fig. 4: The child's utterance 'it has antenna' // it has an*TENna // (Silence threshold (st) is 0.04; voicing threshold (vt) is 0.6 in Praat settings)

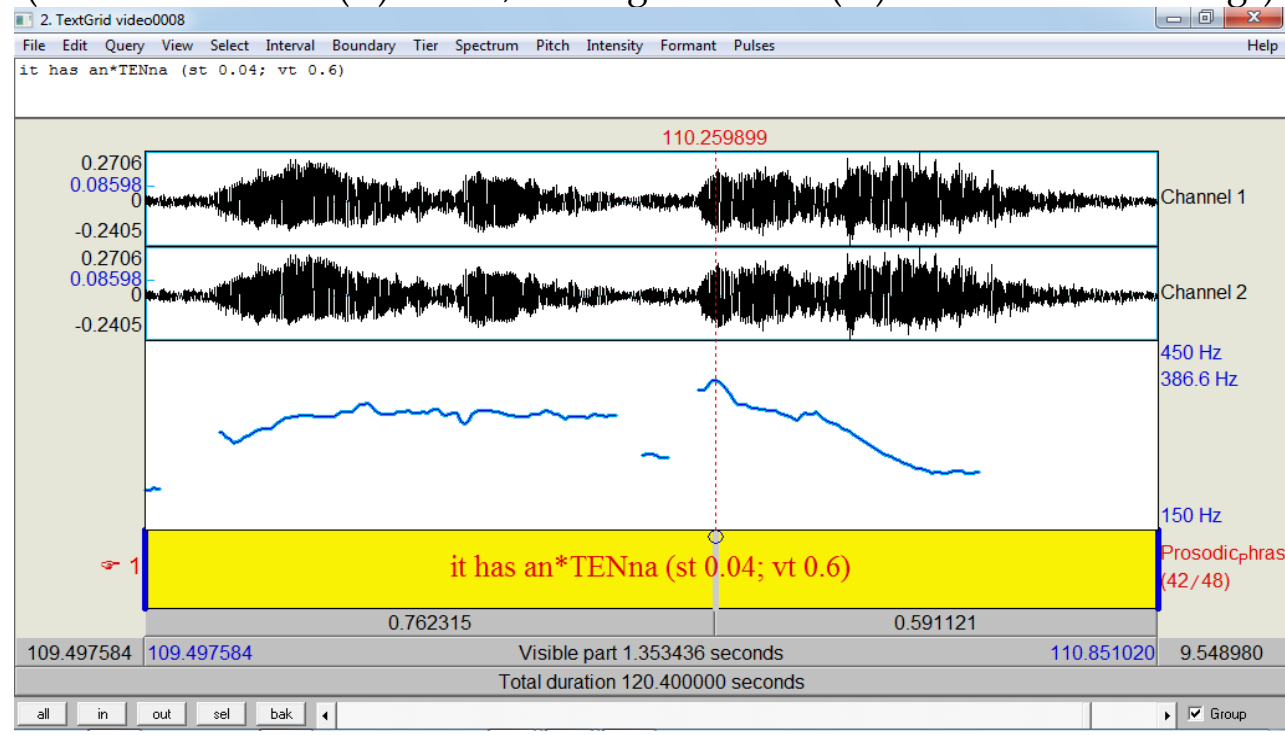

Other examples also show that the child highlights the portions in utterances to indicate the prominence. See Fig. 5 and 6 in which the foci are on *THAT and *THIS* respectively. The marked tonic syllables are in the determiners 'that' and 'this', which are non-lexical words.

Fig. 5: The child's utterance 'like that' // like *THAT //

(Silence threshold (st) is 0.04; voicing threshold (vt) is 0.4 in Praat settings)

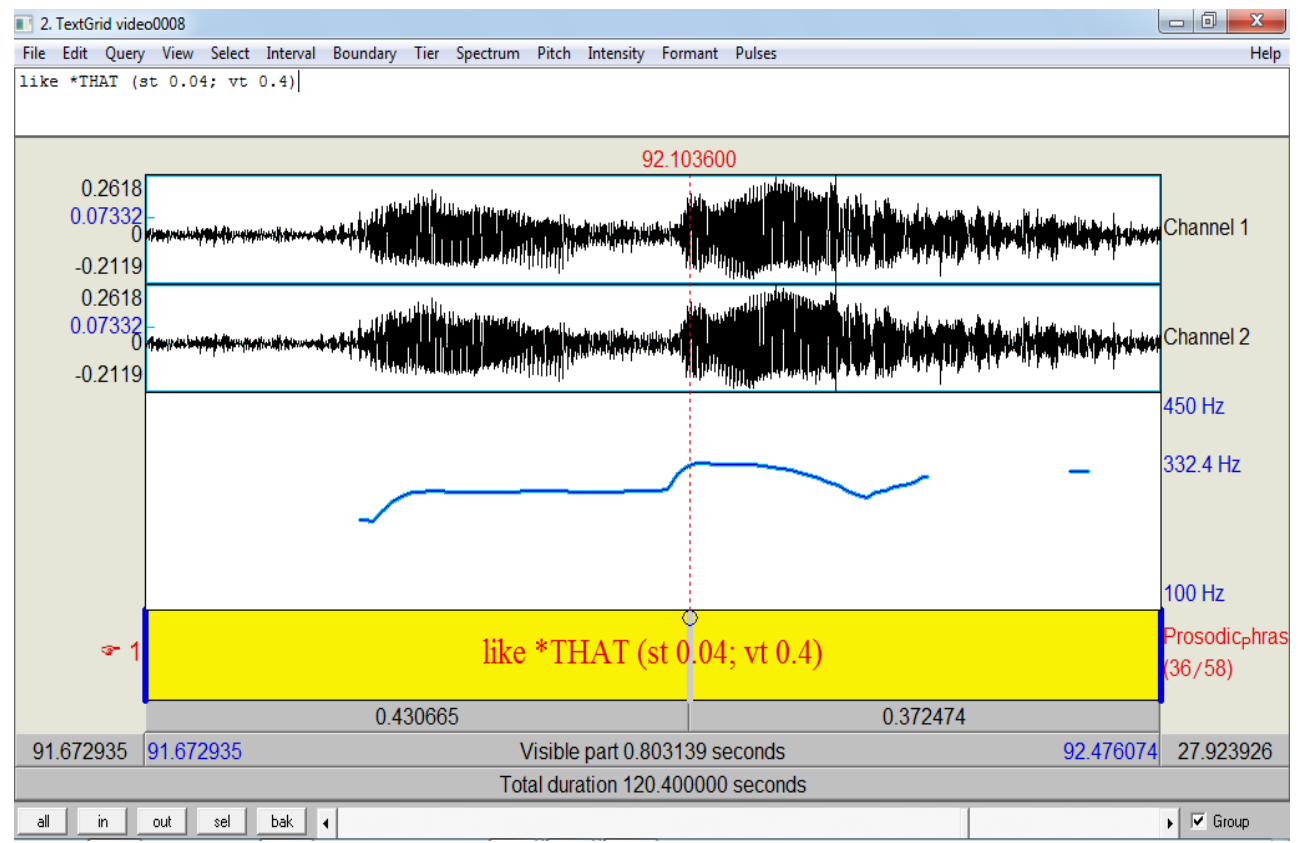


Fig. 6: The child's utterance 'like this for the fire' // like *THIS for the fire // (Silence threshold (st) is 0.04; voicing threshold (vt) is 0.5 in Praat settings

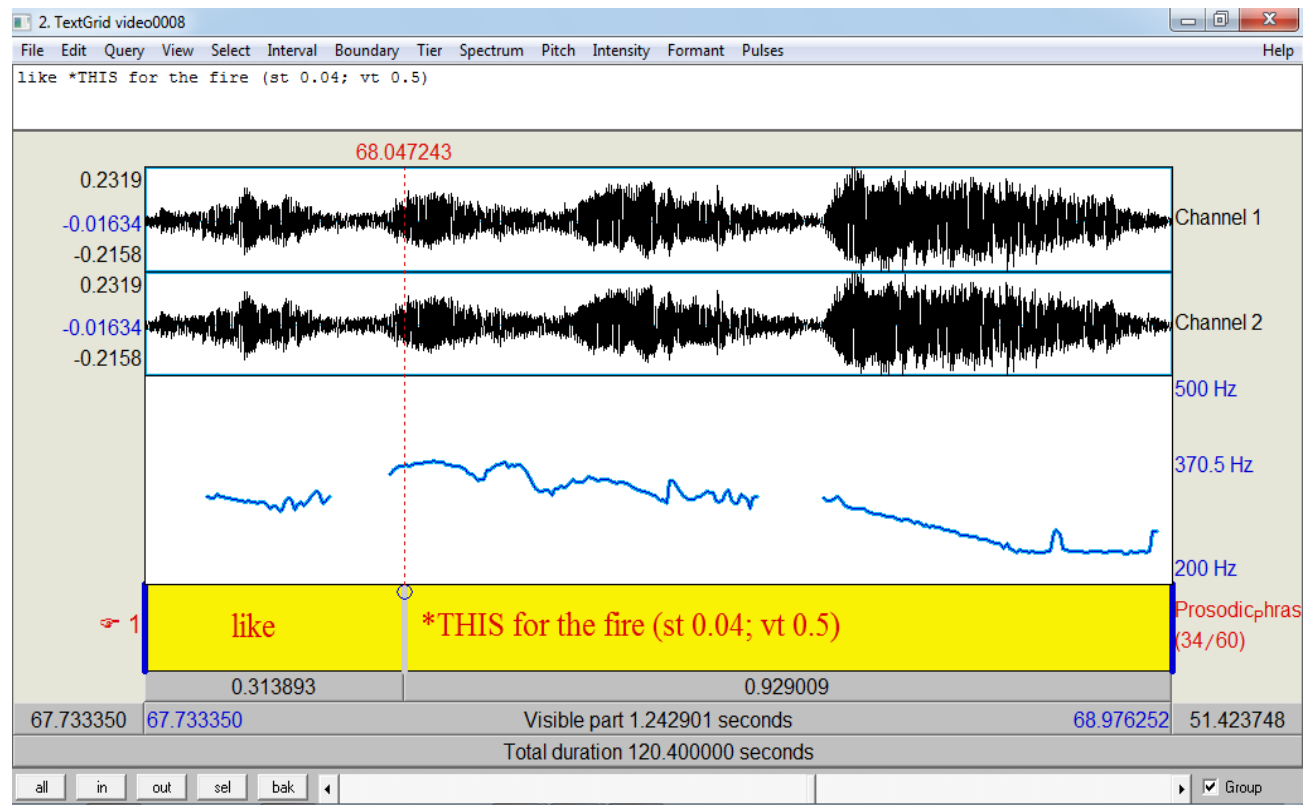

Phonetic analyses demonstrate that the child reliably used prosodic cues to convey the meaning of the utterances. The child used prosodic phrases in terms of tone groups in uttering words as coherent and interpretable units. In addition, the child used prosodic prominence for expressing information focus.

\section{CONCLUSION}

From the analysis of this case study, it can be concluded that the child uses prosodic phrases and intonational prominence. The prosodic phrase is to group words together into interpretable units coherently. Meanwhile, the intonational prominence is to focus marking prosody. In other words, the child has used prosody in language acquisition especially in producing utterances.

It supports the previous researches that children use prosody in their production of utterances and use various aspects of prosody. More specifically, it is on prosodic phrases and intonational prominence in the stream of running speech. Further research will be conducted to see whether the child uses prosody for utterances to convey the intended meaning with disambiguating situational contexts.

\section{REFERENCES}

Boersma, P., \& Weenink, D. (2012). Praat: Doing phonetics by computer [Computer program]. Version 5.3.24, retrieved 9 September 2013 from http://www.praat.org/.

Ito, K. (2002). The interaction of focus and lexical pitch accent in speech production and dialogue comprehension: evidence from Japanese and Basque. PhD dissertation, University of Illinois at UrbanaChampaign.

Ito, K., \& Speer, S. R. (2006). Using interactive tasks to elicit natural dialogue. In Augurzky, P., and Lenertova, D. (Eds.). Methods in empirical prosody research. Leipzig: Mouton de Gruyter.

Halliday, M. A. K., \& Greaves, W. S. (2008). Intonation in the Grammar of English. London: Equinox. 
Johnson, E., \& Jusczyk, P. W. (2001). Word segmentation by 8 month olds: when speech cues count more than statistics. Journal of Memory $\mathcal{E}$ Language 44(5), pp. $48-67$.

Katz, W. F. et al. (1996). Duration and fundamental frequency correlates of phrase boundaries in productions by children and adults. Journal of the Acoustical Society of America 99, pp. 31793191.

Mandel, D. R., Jusczyk, P., \& Pisoni, D. (1995). Infants' recognition of the sound patterns of their own names. Psychological Science, 6, pp. 315-318.

Mehler, et al. (1988). A precursor of language acquisition in young infants. Cognition 29.143-78.
Morgan, J. L. (1996). A rhythmic bias in preverbal speech segmentation. Journal of Memory $\mathcal{E}$ Language, 35, pp. 666 - 688.

Morgan, J. L., \& Saffran, J. R. (1995). Emerging integration of sequential and suprasegmental information in preverbal speech segmentation. Child Development 66(9), pp. 11- 36.

Weber, A., Braun, B., \& Crocker, M. W. (2006). Finding referents in time: eyetracking evidence for the role of contrastive accents. Language and Speech 49(3), pp. 367- 92. 


\section{Appendix 1: Transcript of the child's monologue.}

Welcome to the adventure from below. Now we are ... let a closer look. The new ... Can you see? There's a people on it for here and this is for ... this is for scanning. Ei... ya this is for the scanning. For scanning and we can inside. It has scannning for here body stuff. E... not much because this is for... this is inside of this is. Now now now, it down because it broke. Because it's animal on it. That's why because this is for a gun...wheeeeeuchchh. Like this... like this for the fire...wheeeeeuchchh. Like that. This is not fire lighting. We can see over it for this. Like this... tiiing. This is antenna. This is for the sound wave... ding ding ding. Die. It has antenna. Well everyone thanks watching my TV.

Appendix 2: Some screenshots when the child was explaining in English how his toy worked.
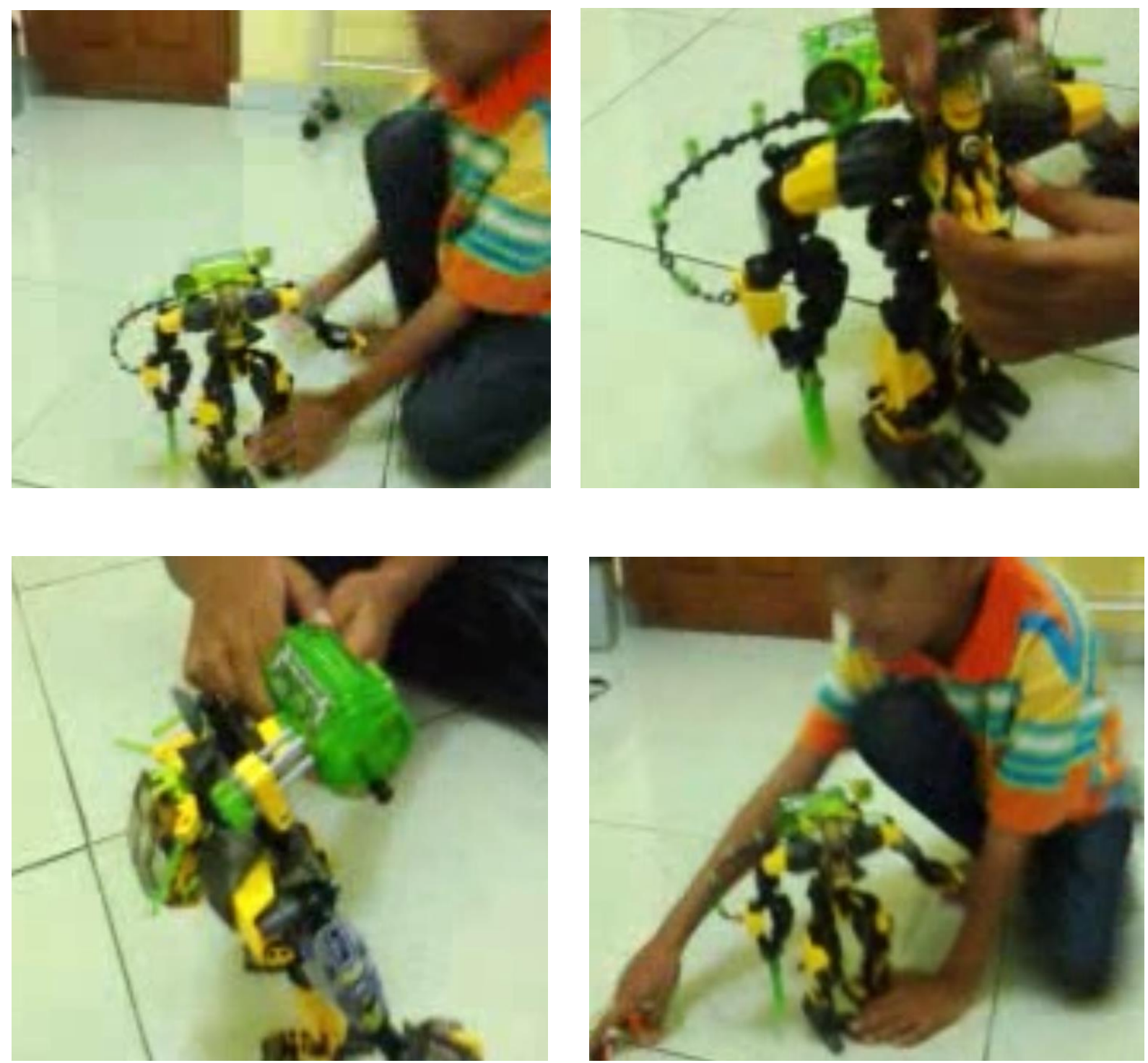